\title{
Traumatic septal coronary perforation after a motor vehicle collision
}

\author{
Wael Abuzeid, ${ }^{1}$ Kareem Morant, ${ }^{2}$ Navneet Singh, ${ }^{3}$ Jeffrey Pang ${ }^{1}$
}

${ }^{1}$ Sunnybrook Health Sciences Centre, Toronto, Ontario, Canada

${ }^{2}$ University of Toronto, Toronto, Ontario, Canada

${ }^{3}$ Medical Imaging, University of Toronto, Toronto, Ontario, Canada

\section{Correspondence to} Dr Wael Abuzeid, wael.abuzeid@mail.utoronto.ca

Accepted 3 January 2017

\section{DESCRIPTION}

A 21-year-old man presented to our institution after a motor vehicle collision. His vitals were normal. He had normal heart sounds with no murmurs.

Electrocardiogram (EKG) showed ST-segment elevations in leads I, AVL.,V1 to V3. Troponin was elevated at $1810 \mathrm{ng} / \mathrm{L}(<15 \mathrm{ng} / \mathrm{L})$. Chest CT revealed multiple rib fractures and a haematoma in the antero-septum of the left ventricle (LV). An echocardiogram revealed mild LV systolic dysfunction with a severely hypokinetic septum and moderate right ventricular (RV) systolic dysfunction. Coronary angiogram showed no evidence of atherosclerosis. There was a traumatic dissection of the second diagonal artery and septal coronary perforation with shunting into the RV (figure 1, videos 1 and 2).

A ventriculogram showed mild global LV systolic dysfunction (video 3). Right heart catheterisation revealed no significant step-up on a shunt run. Cardiac MRI showed a non-significant shunt with QP:QS ratio of 1.04. After discussion with cardiac team and given the lack of a significant shunt as well as clinical stability, a conservative monitoring approach was followed.

On follow-up 10 months later, a CT angiography (CTA) revealed complete resolution of the previously seen haematoma (figure $1 \mathrm{C}$ ) and no evidence of shunt. His echocardiogram was normal.

Blunt chest trauma can cause coronary intimal tear due to shear forces, resulting in dissection

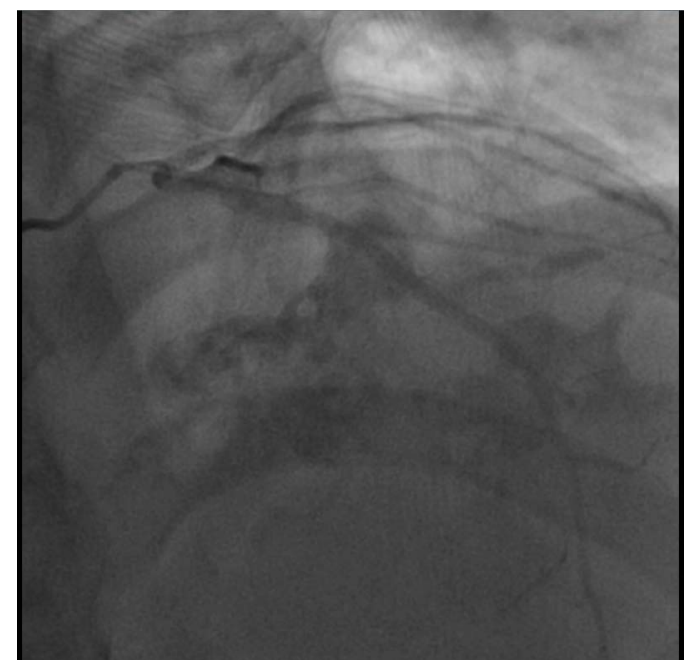

Video 1 Right anterior oblique and cranial shot showing the septal perforation and traumatic dissection of the diagonal branches.

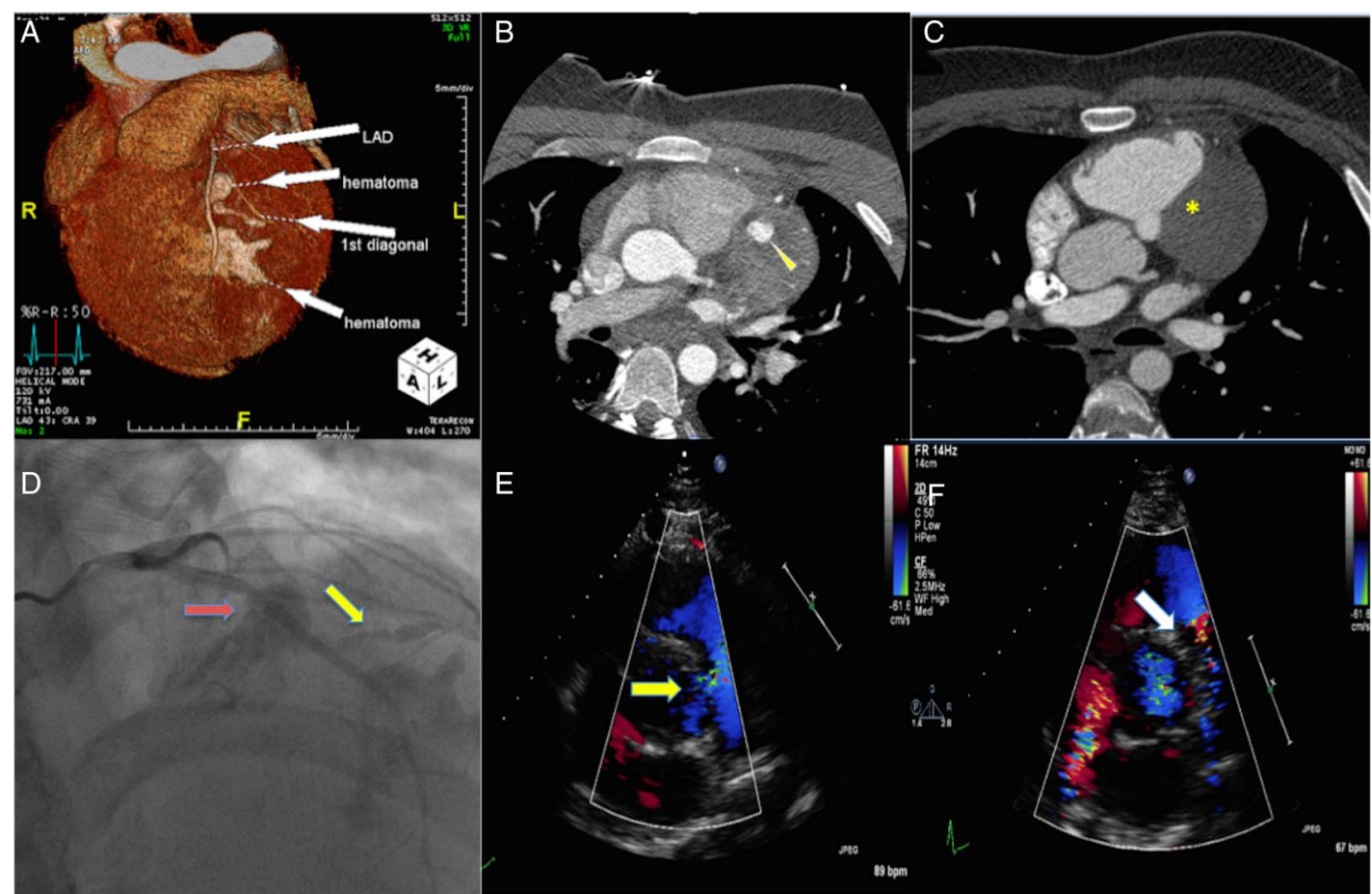

Figure 1 (A) 3D CT reformat demonstrating haematoma adjacent to LAD. (B) Axial CT demonstrating haematoma adjacent to right ventricle (arrowhead). (C) Resolution of haematoma at 3-month (asterisk). (D) Septal haematoma (red arrow) and dissection of second diagonal (yellow arrow). (E) Short-axis view showing continuous flow to the RV (yellow arrow). (F) Resolution of shunt at 10 months (white arrow). 


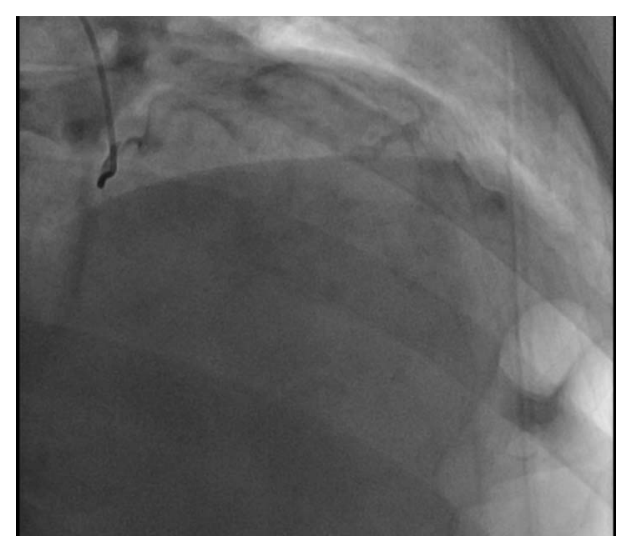

Video 2 Right anterior oblique and cranial shot showing the septal perforation and traumatic dissection of the diagonal branches.

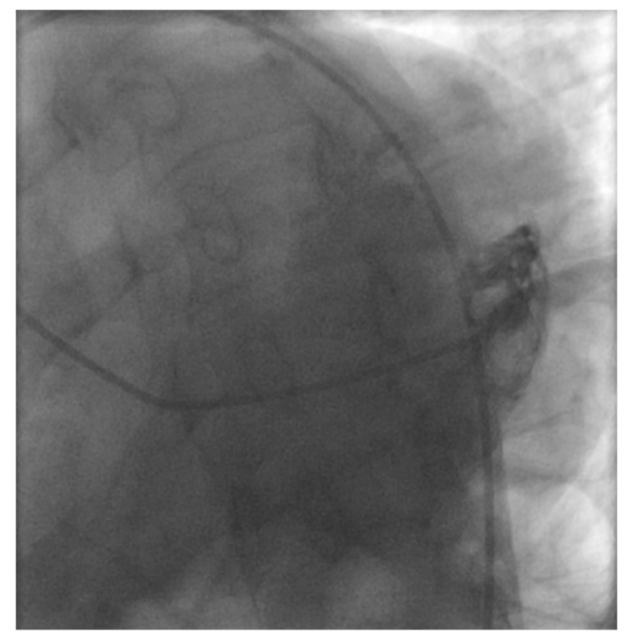

Video 3 A left anterior oblique ventriculogram showing mildly decreased global LV systolic function. LV, left ventricle. and acute myocardial infarction. ${ }^{1}$ The left anterior descending coronary artery (LAD) is mostly affected due to its proximity to the chest wall. ${ }^{2}$ Apart from cardiac contusion, this case highlights traumatic coronary perforation and dissection as a rare complication of motor vehicle accidents.

\section{Learning points}

- Apart from cardiac contusion and spasm, traumatic coronary perforation and dissection should be on the differential diagnosis of blunt chest trauma especially in the context of ECG changes and troponin rise.

- Conservative approach with follow-up CT angiography is reasonable in patients with no chest pain and with preserved TIMI 3 flow in the affected vessel with dissection.

- Septal coronary perforation can lead to VSD that can be monitored with cardiac MRI. Ventricular septal defect (VSD) with a significant shunt usually requires intervention either percutaneously or surgically.

Contributors WA contributed to revision of draft, preparation of figures and submission. KM contributed to the initial draft write-up. NS involved in revision of the draft. JP was the supervisor.

Competing interests None declared.

Patient consent Obtained.

Provenance and peer review Not commissioned; externally peer reviewed.

\section{REFERENCES}

1 Adler JD, Scalea TM. Right coronary artery dissection after blunt chest trauma. Injury Extra 2010;41:77-9.

2 Abdolrahimi SA, Sanati HR, Ansari-Ramandi MM, et al. Acute myocardial infarction following blunt chest trauma and coronary artery dissection. J Clin Diagn Res 2016;10:OD14-5.

Copyright 2017 BMJ Publishing Group. All rights reserved. For permission to reuse any of this content visit http://group.bmi.com/group/rights-licensing/permissions.

BMJ Case Report Fellows may re-use this article for personal use and teaching without any further permission.

Become a Fellow of BMJ Case Reports today and you can:

- Submit as many cases as you like

- Enjoy fast sympathetic peer review and rapid publication of accepted articles

- Access all the published articles

- Re-use any of the published material for personal use and teaching without further permission

For information on Institutional Fellowships contact consortiasales@bmjgroup.com

Visit casereports.bmj.com for more articles like this and to become a Fellow 